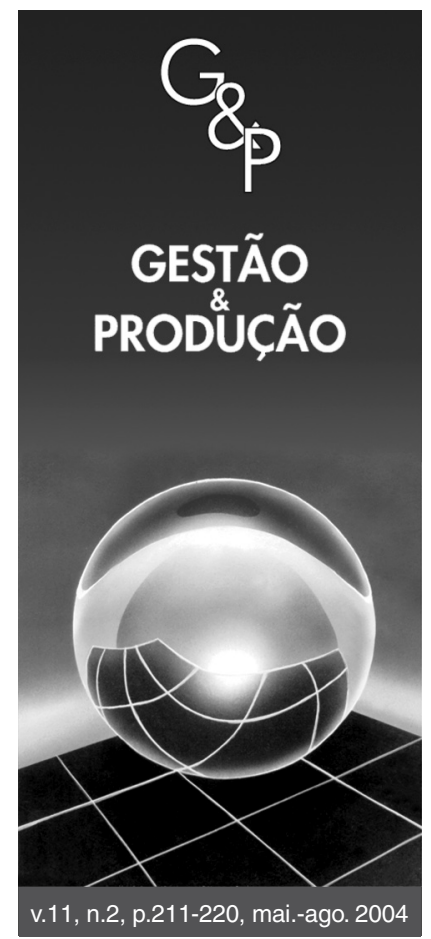

\title{
DETERMINANTES DO GRAU DE ENVOLVIMENTO NA ATIVIDADE EXPORTADORA E SUAS IMPLICAÇÕES NAS EXPORTAÇÕES BRASILEIRAS DE CARNE DE FRANGO
}

\author{
Ynaiá Masse Bueno \\ Gerência de Planejamento e Negócios, \\ Embrapa Transferência de Tecnologia, \\ Parque Estação Biológica, PqEB, Final Av. Ed. Embrapa, \\ Térreo final W3 Norte, CEP 70770-901, Brasília, DF, \\ e-mail: ynaia.bueno@embrapa.br \\ Danilo R. D. Aguiar \\ Departamento de Economia Rural, \\ Universidade Federal de Viçosa, UFV, \\ Avenida P. H. Rolfs s/n, CEP 36570-000, Viçosa, MG, \\ e-mail: danilo@ufv.br \\ Recebido em 28/2/2002 \\ Aprovado em 30/6/2004
}

\section{Resumo}

Este trabalho examina os determinantes do grau de envolvimento na atividade exportadora e verifica as suas implicações para o desempenho das exportações brasileiras da carne de frango. Inicialmente, as empresas foram agrupadas por meio de análise de Cluster. Em seguida, as empresas de cada grupo foram separadas, segundo seu padrão de desempenho, em empresas de maior sucesso e menor sucesso. Os resultados obtidos indicam que a orientação internacional da empresa, sua experiência nas relações com o mercado externo e seu posicionamento competitivo ante os concorrentes destacam-se como os principais determinantes de sucesso das empresas estudadas, pois influenciam positivamente a escolha de estratégias de marketing internacional que proporcionam melhor desempenho. Por outro lado, o estágio do processo de internacionalização, a orientação internacional do administrador e sua experiência nas relações com o mercado externo não apresentaram influência direta na escolha de estratégias de marketing capazes de possibilitar um desempenho satisfatório. Em relação ao tamanho, suas implicações no desempenho das empresas não foram evidenciadas.

Palavras-chave: envolvimento nas exportações, carne de frango, desempenho das exportações.

\section{Introdução}

Desde o final do século $\mathrm{XX}$, a economia mundial vem passando por um processo de profundas transformações. $\mathrm{O}$ desenvolvimento da tecnologia de informação vem aumentando o contato entre os países e impulsionando o processo de globalização. Possivelmente, a maior repercussão da abertura de mercados refere-se à intensificação do comércio internacional. Neste sentido, a globalização oferece a oportunidade de as empresas domésticas ampliarem seu potencial de mercado, possibilitando maior acesso de seus produtos e serviços a mercados estrangeiros. Por outro lado, a livre entrada de mercadorias torna disponível uma grande variedade de produtos, com diferentes padrões de preço e qualidade, que influenciam as decisões de compra dos consumidores e aumentam a concorrência. Além desses fatos, as mudanças nos padrões de consumo exigem que as empresas adotem um estilo de administração capaz de responder às diferentes solicitações no mercado, como forma de atingir seus objetivos e atender às necessidades dos consumidores, de maneira mais eficiente que seus concorrentes.

Para atender às exigências do mercado e competir eficientemente, torna-se essencial que as empresas, além de investirem em tecnologia para aumentar a produtividade e reduzir os custos de produção, estabeleçam estratégias eficazes de marketing, pois, segundo Kotler (1996), além de serem essenciais para criar satisfação aos consumidores e identificar suas necessidades, as estratégias de marketing determinam os melhores mercados que a empresa deve atender, planejam produtos, serviços e programas adequados de preço, promoção e distribuição para satisfazer seus consumidores melhor que seus concorrentes.

Entretanto, para adotar estratégias de marketing internacional que sejam consistentes com a realidade do mercado, é necessário que as empresas apresentem uma estrutura organizacional eficiente, capaz de fornecer vantagens dife- 
renciais e possibilitar que administradores orientados internacionalmente tenham condições de utilizar seus atributos na consecução dos objetivos relativos ao desenvolvimento das exportações. Além disso, é essencial que as empresas tenham elevado grau de envolvimento nas atividades de exportação, pois, dessa forma, tornam-se mais comprometidas e apresentam melhores condições para adotar estratégias de marketing internacional, capazes de sustentar um posicionamento competitivo no mercado.

Em vista dessas considerações, percebe-se que o grau de envolvimento das empresas em suas atividades internacionais é fator decisivo na definição das estratégias de marketing internacional e, conseqüentemente, no desempenho das exportações. Sendo assim, esta pesquisa tem como objetivos identificar os fatores determinantes do grau de envolvimento na atividade exportadora, que, por sua vez, influencia o estabelecimento das estratégias de marketing internacional, e verificar suas implicações no desempenho das exportações de carne de frango, setor em que o Brasil se destaca como o segundo maior exportador mundial.

\section{Metodologia}

\subsection{Referencial teórico}

Em vista da relevância que o mercado internacional apresenta para a definição de políticas públicas e estratégias empresariais, torna-se importante desenvolver um modelo que explique, de forma adequada, os fenômenos associados às atividades de exportação. No presente estudo, três modelos básicos da literatura foram selecionados para subsidiar o modelo proposto: o modelo seqüencial de estágios de exportação, desenvolvido por Bilkey e Tesar (1977), o modelo do grau de envolvimento com a atividade exportadora, proposto por Johnston e Czinkota (1982), e o modelo estruturaestratégia-desempenho, popularizado por Theorelli (1977), citado por Koh (1991).
O modelo seqüencial de estágios de exportação, desenvolvido por Bilkey e Tesar (1977), classifica as empresas desde uma primeira etapa de não interesse em exportação, passando por etapas de crescente comprometimento com a atividade exportadora, até atingir uma atitude de pleno envolvimento com o mercado externo.

O segundo modelo de interesse é o que considera o grau de envolvimento com a atividade exportadora como um potencial determinante do desempenho. Para efetivar esse conceito, Johnston e Czinkota (1982) construíram um índice de motivação, a partir do qual pode-se determinar o grau de envolvimento da empresa com o mercado externo. Este índice consiste em um conjunto de pontos positivos e negativos, atribuídos a cada empresa, dependendo dos motivos que a levaram a exportar serem simples reações a fatores externos ou iniciativas próprias da empresa. Segundo esse princípio, as empresas que adotam uma postura agressiva ou ativa em relação ao mercado externo apresentam condições mais adequadas de alcançarem desempenho satisfatório, enquanto empresas que adotam atitudes passivas ou reativas, têm menores chances de alcançarem um melhor desempenho.

$\mathrm{O}$ terceiro modelo refere-se ao paradigma estrutura-estratégia-desempenho (EED), no qual o desempenho das exportações é influenciado pela estrutura organizacional e pelas estratégias de marketing internacional adotadas pela empresa.

A partir desses três modelos básicos, formulou-se o referencial que está representado na Figura 1. Considera-se que o desempenho das exportações seja determinado pelas estratégias de marketing internacional, que por sua vez seriam resultado do grau de envolvimento da firma no processo exportador. Este elemento seria, por sua vez, resultado do processo de internacionalização e da estrutura organizacional da empresa. Portanto, o desempenho das exportações seria influenciado, diretamente, pela estratégia de marketing internacional adotada e, indiretamente, pelos demais elementos do modelo.

Para um maior detalhamento dos componentes do modelo,

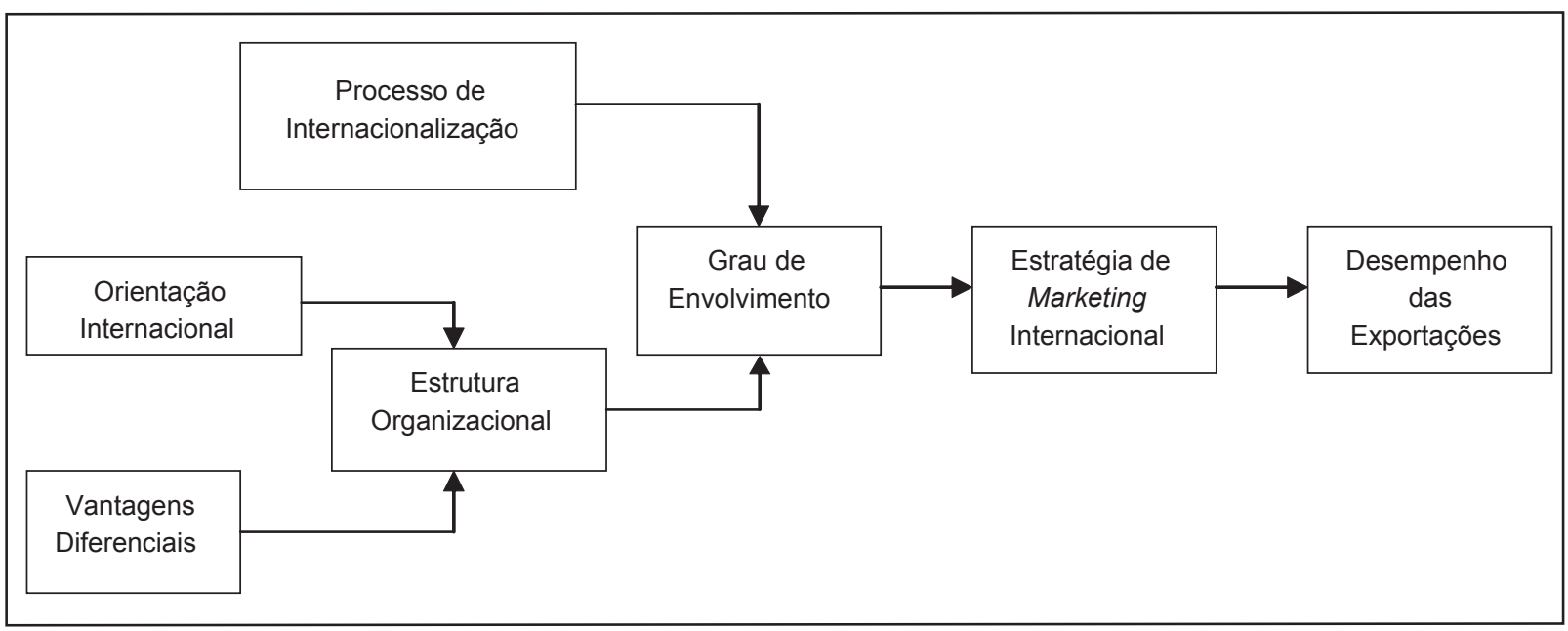

Figura 1. O desempenho das exportações resultante das estratégias de marketing internacional. 
deve-se considerar que a estrutura organizacional não é exógena, sendo determinada por outros dois elementos: a orientação internacional e as vantagens diferenciais da empresa. A orientação internacional compreende variáveis relacionadas a fatores da organização e da administração. Procura mostrar se a empresa adota uma postura ativa ou reativa nas relações com o mercado externo, bem como se os administradores apresentam-se voltados para o mercado internacional ou para o mercado interno. As vantagens diferenciais são variáveis relacionadas às características da organização e ao seu posicionamento competitivo no mercado. Essas variáveis prevalecem como determinantes de diversas vantagens que influenciam a tomada de decisões e o desempenho das exportações e buscam determinar a eficácia da empresa em relação a seus concorrentes no que diz respeito a fatores relacionados às estratégias operacionais de marketing.

Em vista dessas considerações, o modelo proposto considera que o grau de envolvimento das empresas nas atividades de exportação, definido em função das variáveis dos estágios do processo de internacionalização e da estrutura organizacional, determina as estratégias de marketing internacional. Sendo assim, as empresas dotadas de conhecimentos, experiências e comprometimento em relação ao mercado externo teriam maior envolvimento com o comércio internacional e teriam melhores condições para adotar estratégias adequadas e garantir o sucesso das exportações.

Embora fundamentais para a compreensão do sucesso das exportações, as estratégias de marketing internacional são consideradas apenas indiretamente nesta pesquisa. Esse fato decorre da relutância das empresas em concederem informações consistentes sobre suas estratégias e de suas ambíguas relações com o desempenho, visto que estratégias muito divergentes podem ter resultado de determinadas condições da estrutura organizacional e diferentes desempenhos podem ter origem em estratégias supostamente similares. Dessa forma, embora o modelo estabeleça que são as estratégias de marketing internacional que determinam o desempenho exportador, o foco do trabalho é nos elementos definidores do grau de envolvimento da empresa na atividade de exportação e na relação desses elementos com o desempenho. Faz-se, portanto, uma ligação direta entre o grau de envolvimento e o desempenho exportador.

\subsection{Variáveis básicas e dados}

Dado o caráter multidimensional dos conceitos relacionados ao desenvolvimento de estratégias de marketing internacional, a avaliação desse processo requer a consideração de um conjunto de variáveis capazes de captar seus fatores associados. Além disso, a caracterização das variáveis foi realizada por meio da utilização de variáveis multi-itens. O objetivo da utilização dessa técnica consiste em aumentar a validação das medições, visto que em alguns casos, uma única medida para explicar o significado de uma variável não é suficiente.

Lee (1987), citado por Silva (1997), propõe a utilização dessa técnica da seguinte maneira: para cada uma das variáveis $\left(\mathrm{V}_{\mathrm{i}}\right)$, vários itens $\left(\mathrm{V}_{\mathrm{ij}}\right)$ são considerados, com base em uma escala intervalar utilizada para determinar a composição dos escores de cada variável, quando assim for necessário, sendo definida pela seguinte equação:

$$
\mathrm{V}_{\mathrm{i}}=\sum_{j=i}^{n} \mathrm{~V}_{\mathrm{ij}}
$$

Com base na revisão de literatura e no método proposto nesta pesquisa, diversas variáveis foram consideradas como influenciadoras do grau de envolvimento nas atividades de exportação e, por conseguinte, das estratégias de marketing internacional. No total, trinta variáveis foram usadas com tal objetivo, as quais se encontram apresentadas no Quadro 1. Para descrever o desempenho das empresas exportadoras, quatro variáveis foram utilizadas, conforme mostra o Quadro 2.

O levantamento de informações para compor as variáveis baseou-se na elaboração e aplicação de um questionário, que foi enviado, por meio da Associação Brasileira dos Produtores e Exportadores de Frangos (ABEF), para suas 21 associadas, responsáveis por $96,6 \%$ das exportações brasileiras de carne de frango, em 2000. No entanto, por diferentes razões, apenas 10 empresas responderam ao questionário, as quais compõem a amostra desta pesquisa. A partir das informações obtidas no questionário, as variáveis foram mensuradas conforme descreve o Quadro A1, do Apêndice.

Embora representem um número pequeno, principalmente para fins de análises estatísticas, sua representatividade pode ser considerada expressiva, visto que essas 10 empresas responderam por, aproximadamente, $56 \%$ das exportações brasileiras de carne de frango, em 1999. Para preservar a identidade das empresas no presente trabalho, a elas são atribuídos números sequienciais, de 1 a 10.

\subsection{Método empírico}

Em um primeiro momento, a identificação dos fatores que determinam o grau de envolvimento nas atividades de exportação e das estratégias de marketing internacional foi realizada por meio da análise de Cluster, de forma semelhante ao que foi feito por Barbosa (1991). A análise de Cluster, ou análise de agrupamento, consiste em uma técnica de análise multivariada em que a amostra é classificada em um pequeno número de grupos, mutuamente exclusivos, baseados nas similaridades entre os indivíduos. Assim, é uma técnica utilizada para identificar grupos, que envolve pelo menos dois passos: (1) medir alguma forma de similaridade ou associação entre as variáveis utilizadas para determinar quantos grupos realmente existem na amostra; e (2) traçar o perfil das variáveis para determinar sua composição.

Quanto ao procedimento usado para designar, dentro dos grupos, os indivíduos semelhantes, utilizam-se algoritmos que buscam maximizar as diferenças entre grupos em relação às variações dentro dos grupos. Dentre estes algoritmos, os mais comumente utilizados podem ser classificados em duas categorias gerais: hierárquicos e não-hierárquicos (Hair Jr., 1979). 
Quadro 1. Variáveis definidoras do grau de envolvimento na atividade exportadora e suas formas de utilização.

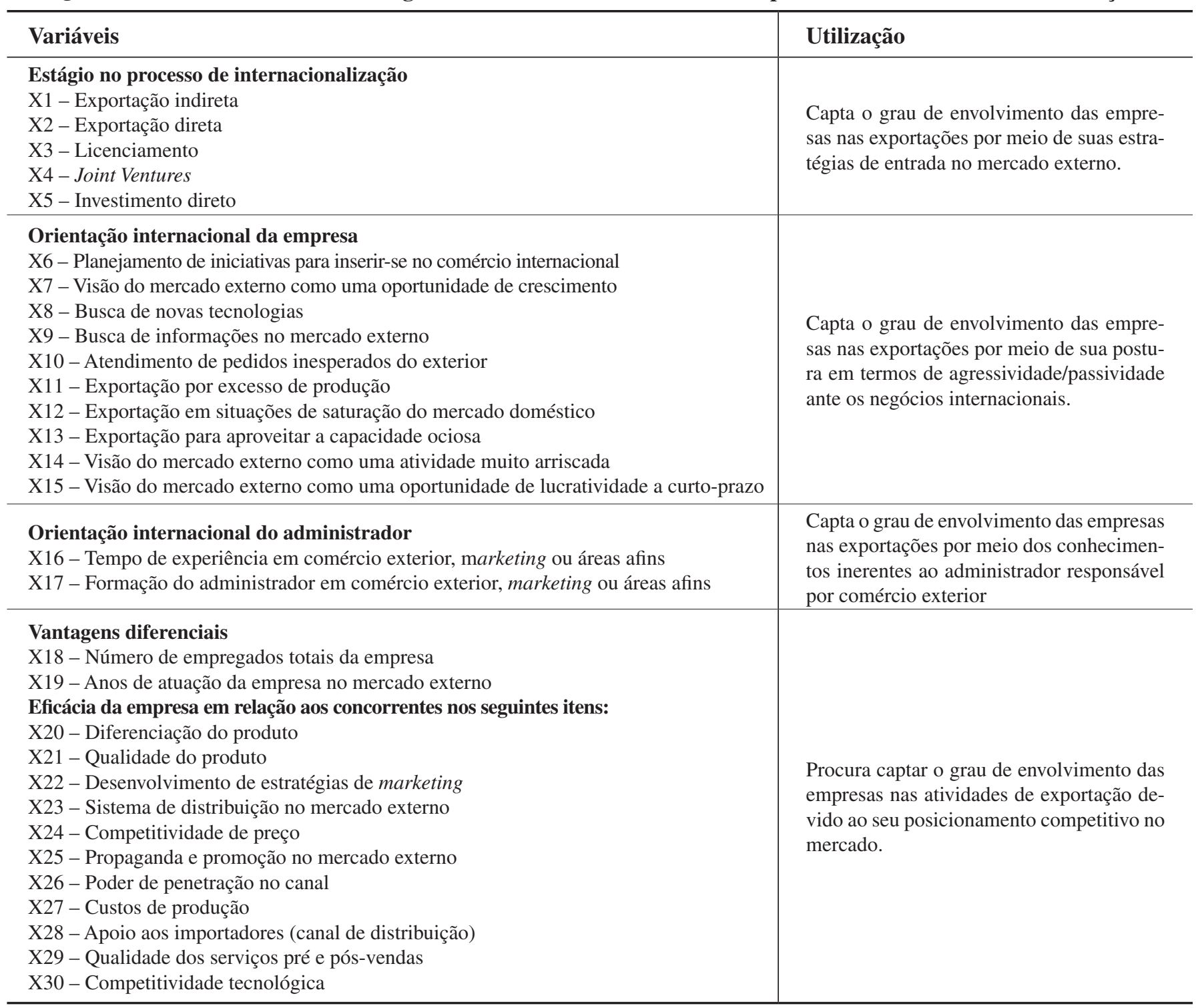

Quadro 2. Variáveis definidoras do desempenho das exportações.

\begin{tabular}{l}
\hline Variáveis \\
\hline X31 - Desempenho das exportações de carne de frango em \\
relação ao mercado interno \\
X32 - Participação das exportações de carne de frango em \\
relação às vendas totais da empresa \\
X33 - Número de mercados para os quais a empresa exporta \\
X34 - Taxa de crescimento das exportações em relação à indústria \\
\hline
\end{tabular}

Os procedimentos não-hierárquicos designam os indivíduos aos grupos num processo em que o número de grupos deve ser previamente definido. Já os procedimentos hierárquicos consistem, basicamente, na formação de uma estrutura hierárquica, podendo seguir a via aglomerativa ou divisiva. Enquanto os métodos aglomerativos consistem, em cada passo, na união de um indivíduo a outro indivíduo ou ao grupo formado no passo anterior, de modo que ao final, todos os indivíduos pertençam a um único grupo, os métodos divisivos simplesmente realizam o caminho inverso.

Entre os métodos utilizados, os mais comuns classificamse no grupo das técnicas hierárquicas aglomerativas, em que a classificação dos indivíduos é feita mediante sucessivas fusões dos $n$ indivíduos em grupos. O objetivo final das técnicas desse grupo é a redução dos dados originais a um único Cluster contendo todos os indivíduos.

O procedimento básico consiste em computar uma matriz de distância ou similaridade entre os indivíduos, a partir da qual se inicia um processo de sucessivas fusões, com base na proximidade ou similaridade entre eles. Essa matriz é simétrica $\left(\mathrm{d}_{\mathrm{AB}}=\mathrm{d}_{\mathrm{AB}}\right)$, com zeros na diagonal principal, e é obtida mediante vários métodos, sendo um dos mais comuns a distância euclidiana, que é expressa matematicamente por

$$
\mathrm{d}_{(\mathrm{A} . \mathrm{B})}=\left[\sum_{i=1}^{0}\left(\mathrm{X}_{\mathrm{i}(\mathrm{A})-} \mathrm{X}_{\mathrm{i}(\mathrm{B})}\right)^{2}\right]^{1 / 2}
$$


Em que $\mathrm{d}_{(\text {A.B })}=$ medida de distância euclidiana do indivíduo $a$ ao $b ; i$ está indexando as variáveis. Se a distância euclidiana for próxima de zero, significa que os objetos comparados são similares.

Os métodos de análise de agrupamento buscam sempre maximizar o objetivo de obter coesão interna entre os dados e o isolamento externo entre eles. Um método de interpretação dos resultados da análise de agrupamentos dá-se por meio do método gráfico denominado dendrograma, que nada mais é do que um diagrama bidimensional que exibe as fusões realizadas em cada nível, culminando no estágio em que todos os indivíduos estão num único grupo.

Na decisão de quantos Clusters ou grupos devem ser necessários para representar os dados, costuma-se observar o coeficiente da distância euclidiana dos Clusters combinados e o dendrograma, quando o critério de solução ocorre pelo método hierárquico. Pequenos coeficientes indicam que Clusters homogêneos estão sendo formados, enquanto grandes coeficientes indicam que os Clusters contêm casos heterogêneos. Como guia, recomenda-se que o agrupamento deve parar quando o coeficiente decresce consideravelmente de um passo para o outro.

Depois de o número de Clusters ter sido decidido, as características de cada grupo foram estudadas, por meio de procedimentos estatísticos tal como a análise de frequiência, que permite averiguar a importância relativa das variáveis determinantes do grau de envolvimento das empresas nas atividades de exportação.

Segundo Stevenson (1981), a distribuição de freqüência é um método de agrupamento de dados em classes ou intervalos, de tal forma que se possa determinar o número ou a percentagem de cada classe. Esse método proporciona uma forma de visualizar um conjunto de variáveis sem levar em consideração sua situação individual, podendo ter grande utilidade quando precisamos lidar com grande quantidade de dados.

Após terem sido identificadas as características das empresas envolvidas nas atividades de exportação, identificaram-se os fatores determinantes das estratégias de marketing internacional e do sucesso das exportações. Para isso, as empresas de cada grupo foram classificadas de acordo com seu padrão de desempenho.

Segundo Silva (1997), diversos autores (Samiee e Walters, 1990; Madsen, 1989; Cooper e Kleinschmidt, 1985) utilizam medidas múltiplas para explicar o desempenho das exportações sob a crença de que estas oferecem um melhor guia para a tomada de decisões. A justificativa de sua utilização consiste em oferecer uma melhor visão do desempenho, visto que diferentes aspectos podem ser afetados por diferentes características da empresa.

Em vista dessas considerações, para medir o desempenho foi utilizada a metodologia proposta por Ayal (1982). Primeiramente, as informações referentes ao desempenho foram obtidas por meio de medidas que poderiam ser consideradas como indicadores parciais do sucesso. Dessa forma, quatro indicadores foram selecionados para cada empresa, correspondentes às variáveis de X31 a X34 do Quadro 2.
Conhecidos os pareceres de cada empresa em relação às medidas parciais de desempenho, essas variáveis foram codificadas com um valor numérico representando a situação da empresa em termos de desempenho, que se distinguiam em superior (2), médio (1), ou inferior (0). Em seguida, um índice combinado de sucesso para cada empresa foi calculado por meio da soma das quatro medidas de desempenho parcial. O valor mínimo possível para o índice foi 0 e o máximo foi 8. A média e o desvio padrão indicaram o intervalo de classificação das empresas nos níveis de desempenho.

A análise estatística permite identificar os fatores determinantes das estratégias de marketing internacional e suas implicações no desempenho exportador. Tal identificação mostra-se importante por prover informações capazes de auxiliar a tomada de decisão das empresas com potencial exportador, propiciando-lhes condições de alcançar uma posição de sucesso no competitivo mercado internacional.

\section{Resultados e discussões}

A partir da análise de Cluster, aplicada para classificar as empresas segundo o grau de envolvimento no mercado (Figura 2), as empresas exportadoras de carne de frango participantes desta pesquisa foram divididas em três grupos, distintamente denominados de Grupo A, Grupo B e Grupo $\mathrm{C}$, sendo cada um, respectivamente, composto de duas (2 e 9), três (3, 5 e 7$)$ e cinco $(1,4,6,8$ e 10) empresas. Os resultados das avaliações das trinta variáveis fundamentais do modelo (excluindo-se as quatro variáveis definidoras do desempenho, que serão analisadas mais adiante) estão apresentados na Tabela 1.

Os resultados da análise Cluster permitiram também inferir que algumas empresas diferiram das demais em termos do grau de envolvimento nas atividades de exportações, dentro de um mesmo grupo. Essa situação pode ser explicada pelo fato de que a estrutura organizacional das empresas e o estágio do processo de internacionalização em que se encontram podem variar, de uma empresa para outra. Entretanto, é importante ressaltar que essas diferenças são essenciais para atingir os objetivos desta pesquisa, visto que possibilitam a verificação dos fatores que influenciam a definição de estratégias de marketing internacional e suas principais implicações no desempenho.

No que diz respeito ao Grupo A, a análise mostrou que o envolvimento das empresas dispostas nesse grupo pode ser explicado pelo estágio avançado em que se encontram em relação ao processo de internacionalização, pela experiência da empresa e do administrador nas relações com o mercado externo e pelo nível de instrução do gerente responsável pelo setor de exportação. Entretanto, essas empresas atuam de forma passiva no que diz respeito à orientação internacional da empresa e ao seu posicionamento diante dos concorrentes no mercado internacional.

Em relação ao Grupo B, o envolvimento das empresas dentro do grupo diferiu no que diz respeito ao estágio do processo 
Tabela 3. Resultados dos questionários aplicados nas empresas exportadoras de carne de frango.

\begin{tabular}{|c|c|c|c|c|c|c|c|c|c|c|}
\hline \multirow{2}{*}{$\begin{array}{l}\text { Variáveis/ } \\
\text { Empresas }\end{array}$} & \multirow{2}{*}{\multicolumn{2}{|c|}{$\begin{array}{c}\text { Grupo A } \\
29\end{array}$}} & \multicolumn{3}{|c|}{ Grupo B } & \multicolumn{5}{|c|}{ Grupo C } \\
\hline & & & 3 & 5 & 7 & 1 & 4 & 6 & 8 & 10 \\
\hline $\mathrm{X} 1$ & 4 & 3 & 1 & 3 & 4 & 1 & 1 & 1 & 1 & 1 \\
\hline $\mathrm{X} 2$ & 3 & 4 & 5 & 4 & 0 & 5 & 5 & 5 & 5 & 5 \\
\hline X3 & 1 & 1 & 1 & 1 & 1 & 1 & 1 & 1 & 1 & 1 \\
\hline $\mathrm{X} 4$ & 1 & 1 & 1 & 1 & 1 & 1 & 1 & 1 & 1 & 1 \\
\hline $\mathrm{X} 5$ & 4 & 4 & 1 & 1 & 1 & 1 & 3 & 1 & 1 & 4 \\
\hline X6 & 2 & 2 & 5 & 2 & 2 & 4 & 5 & 5 & 3 & 4 \\
\hline X7 & 3 & 2 & 5 & 4 & 4 & 5 & 5 & 2 & 4 & 4 \\
\hline $\mathrm{X} 8$ & 2 & 2 & 2 & 2 & 2 & 3 & 4 & 3 & 3 & 4 \\
\hline X9 & 2 & 4 & 3 & 3 & 3 & 4 & 5 & 5 & 4 & 4 \\
\hline $\mathrm{X} 10$ & 2 & 2 & 2 & 3 & 3 & 2 & 2 & 2 & 2 & 2 \\
\hline X11 & 3 & 3 & 2 & 2 & 4 & 2 & 2 & 2 & 2 & 2 \\
\hline $\mathrm{X} 12$ & 2 & 3 & 2 & 2 & 3 & 2 & 2 & 2 & 2 & 2 \\
\hline X13 & 3 & 3 & 2 & 2 & 2 & 2 & 2 & 2 & 3 & 3 \\
\hline X14 & 2 & 2 & 2 & 2 & 3 & 2 & 2 & 2 & 3 & 2 \\
\hline X15 & 3 & 3 & 2 & 3 & 4 & 2 & 2 & 2 & 3 & 3 \\
\hline X16 & 2 & 2 & 2 & 2 & 0 & 1 & 0 & 2 & 1 & 2 \\
\hline X17 & 1 & 1 & 0 & 0 & 0 & 0 & 0 & 1 & 1 & 0 \\
\hline X18 & 1 & 1 & 0 & 1 & 0 & 1 & 2 & 2 & 1 & 1 \\
\hline X19 & 2 & 2 & 0 & 0 & 0 & 1 & 2 & 1 & 1 & 0 \\
\hline X20 & 2 & 2 & 5 & 4 & 2 & 4 & 3 & 5 & 3 & 4 \\
\hline X21 & 2 & 3 & 5 & 4 & 3 & 4 & 3 & 5 & 3 & 4 \\
\hline X22 & 2 & 2 & 3 & 3 & 3 & 3 & 3 & 5 & 3 & 3 \\
\hline X23 & 2 & 2 & 5 & 3 & 3 & 3 & 3 & 3 & 3 & 4 \\
\hline X24 & 3 & 4 & 3 & 4 & 2 & 3 & 5 & 3 & 4 & 4 \\
\hline $\mathrm{X} 25$ & 2 & 2 & 3 & 3 & 3 & 3 & 3 & 3 & 3 & 0 \\
\hline X26 & 3 & 2 & 5 & 4 & 3 & 3 & 3 & 5 & 4 & 4 \\
\hline X27 & 3 & 2 & 3 & 3 & 3 & 3 & 2 & 3 & 2 & 3 \\
\hline X28 & 2 & 2 & 3 & 3 & 3 & 4 & 3 & 5 & 4 & 4 \\
\hline X29 & 2 & 2 & 3 & 4 & 3 & 3 & 3 & 5 & 4 & 4 \\
\hline X30 & 2 & 2 & 3 & 4 & 2 & 3 & 3 & 3 & 4 & 4 \\
\hline
\end{tabular}

Nota: Para compreender as avaliações mostradas neste quadro, ver Figura 2.

de internacionalização, orientação internacional da empresa e posicionamento competitivo ante os concorrentes. Segundo os resultados obtidos, a Empresa 3 mostrou-se mais ativa que as outras empresas, visto que realiza suas operações com o mercado externo de maneira planejada, utiliza a exportação direta como meio de entrar no mercado e dispõe de um posicionamento eficaz em relação aos concorrentes, principalmente em termos de diferenciação do produto, qualidade e poder de penetração no canal de distribuição. Entretanto, o envolvimento do grupo fica comprometido em termos de orientação do administrador, visto que não dispõe de gerentes com formação em comércio exterior, ou áreas afins, e em termos de vantagens diferenciais da empresa, visto que as empresas têm um porte pequeno e pouca experiência no mercado.

Ao se tratar do Grupo C, pode-se dizer que suas empresas são altamente envolvidas com os negócios internacionais, pois realizam suas atividades de forma planejada, buscando informações sobre o mercado consumidor e os concorrentes e preocupam-se com o acesso às novas tecnologias. Além disso, essas empresas mostram-se experientes nas relações com o mercado externo, apresentam um tamanho considerável e adotam uma atitude agressiva diante dos concorrentes. Todas utilizam a exportação direta como forma de entrada no mercado internacional, e $40 \%$ também adotam o investimento direto (4 e 10). O menor envolvimento dessas empresas revela-se apenas em termos de orientação administrativa, visto que apenas $40 \%$ de administradores são formados em comércio exterior ou áreas afins. Em relação a esse grupo, é importante ressaltar que duas empresas (8 e 10) encontramse um pouco menos envolvidas nas atividades de exportação, pois apresentam interesses de curto prazo e, muitas vezes, exportam apenas para aproveitar capacidade ociosa.

Identificados os fatores que influenciam o envolvimento das empresas nas atividades de exportação, as empresas exportadoras de carne de frango foram classificadas, segundo seu padrão de desempenho. Com base em um índice geral de desempenho, as empresas de sucesso foram comparadas, por meio da análise de frequiência, com as empresas de menor sucesso, segundo seu grau de envolvimento nas atividades de exportação. Essa comparação pretende revelar as principais implicações que o grau de envolvimento no mercado tem sobre o desempenho das exportações de carne de frango.

Embora os resultados parciais retratem diferenças significativas, o índice geral de desempenho, disposto no Tabela 2, indica que as empresas de maior sucesso nas atividades de exportação de carne de frango pertencem ao Grupo B (Empresa 3) e ao Grupo C (Empresas 1, 4 e 6). Já as empresas do Grupo A, juntamente com as empresas não citadas dos outros grupos, apresentaram desempenho inferior.

Conforme anteriormente salientado, o desempenho das exportações é função das estratégias de marketing internacional, que por sua vez, são influenciadas pelo grau de envolvimento da empresa com o mercado externo. Segundo esse conceito, as empresas envolvidas nas atividades de exportação, apresentam-se mais comprometidas com o mercado internacional e encontram-se mais aptas a atingir melhor desempenho. Dentro desse contexto, a verificação dos determinantes de sucesso das empresas exportadoras de carne de frango foi realizada por meio da análise do estágio do processo de internacionalização em que se encontram as empresas, dispostas em diferentes grupos, e de sua estrutura organizacional. 


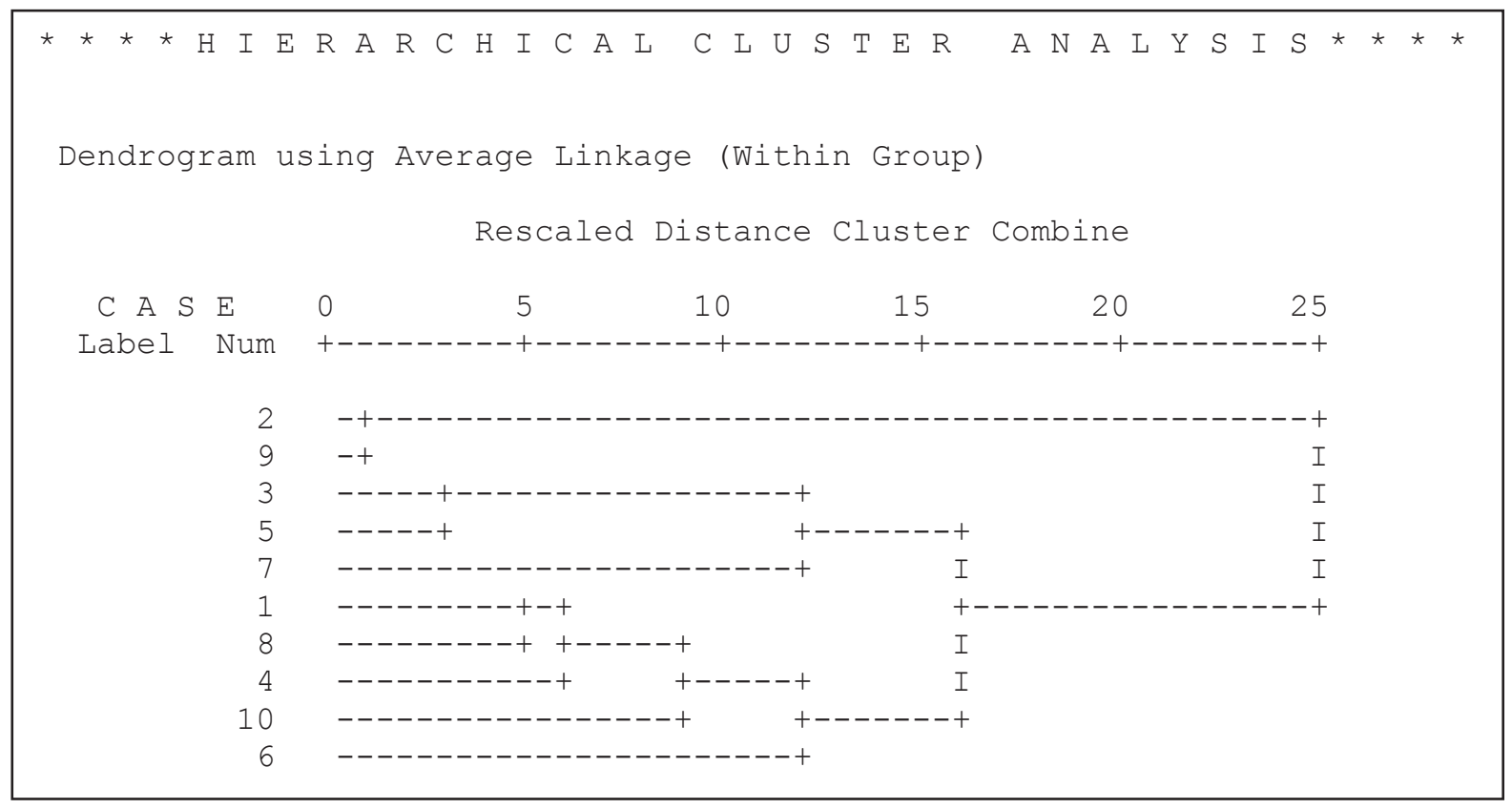

Figura 2. Representação da classificação hierárquica - dendrograma.

Se IGD $\geq 4$, as empresas são consideradas como apresentando um desempenho superior.

Apesar de refletir um maior comprometimento e envolvimento com o mercado externo, o estágio do processo de internacionalização, de acordo com os resultados analisados, não parece atuar decisivamente na definição de estratégias de sucesso para as empresas exportadoras de carne de frango. Isso pode ser evidenciado pelo fato de que apenas uma empresa do Grupo C (Empresa 4) que utilizou o investimento direto como forma de entrada no mercado internacional, apresentou desempenho satisfatório. As outras empresas que utilizaram esse tipo de estratégia (Empresas 2 e 9, do Grupo A e Empresa 10, do Grupo C), apresentaram pior desempenho. No entanto, é importante ressaltar que todas as empresas de sucesso apresentam-se envolvidas nas atividades com o mercado internacional, visto que utilizam a exportação direta como forma de atuar em seus respectivos mercados.

Em relação à estrutura organizacional da empresa, conforme já comentado, os fatores que influenciam as estratégias de marketing e o desempenho das exportações foram subdivididos em orientação internacional e vantagens diferenciais. De modo geral, as empresas e os administradores orientados internacionalmente adotam uma postura ativa diante dos negócios com o mercado externo e atuam de maneira planejada, reagindo estrategicamente às questões inerentes ao mercado. Seu crescente envolvimento possibilita condições mais adequadas para adotar estratégias de marketing eficientes capazes de garantir um desempenho satisfatório.

Segundo os resultados obtidos, empresas orientadas internacionalmente realmente apresentam melhores condições para elaborar estratégias de marketing condizentes com a realidade do mercado e alcançam melhores desempenhos. A evidência desses resultados revela-se pelo fato de que todas as empresa de sucesso adotaram posturas ativas em suas relações com o mercado externo, contrariamente às empresas de menor sucesso, que adotaram atitudes passivas em suas relações com o exterior.

No que diz respeito à orientação dos administradores, esperava-se que o nível de instrução proporcionasse certas vantagens relativas ao conhecimento, que auxiliariam na adoção de estratégias de marketing eficientes. Porém, os resultados obtidos nesta pesquisa não confirmam sua relevância, visto que apenas uma empresa de sucesso (Empresa 6, do Grupo C) dispõe de administradores formados em comércio exterior e áreas afins. Em contrapartida, as empresas do Grupo A, com desempenho inferior, possuem administradores com nível superior em sua área de atuação, sugerindo que a orientação internacional dos administradores não apresenta implicações sobre a escolha adequada de estratégias que proporcionem um melhor desempenho.

Para analisar as vantagens diferenciais da empresa, conforme já comentado, o tamanho da empresa e sua experiência no mercado internacional foram designados para caracterizar a organização, considerando que ocasionam certas vantagens que influenciam a tomada de decisão e o desempenho das exportações. Mas de acordo com a análise realizada, resultados controversos não possibilitam a inferência sobre a influência do tamanho da empresa como fator relevante nas decisões referentes aos negócios internacionais e em suas relações com o desempenho das exportações. De maneira geral, espera-se que empresas maiores sejam mais eficientes, devido a diversas vantagens associadas ao tamanho. Nesse aspecto, as Empresas 4 e 6, do Grupo C, encaixam-se nesse contexto, visto que apresentam tamanho relevante e desempenho superior. Entretanto, a Empresa 3, do Grupo B, é pequena e também apresenta desempenho 
Tabela 2. Índice geral de desempenho e seus indicadores parciais.

\begin{tabular}{ccccccc}
\hline Empresas & & $\mathbf{X 3 1}$ & $\mathbf{X 3 2}$ & $\mathbf{X 3 3}$ & $\mathbf{X 3 4}$ & $\begin{array}{c}\text { Índice Geral de } \\
\text { desempenho }\end{array}$ \\
\hline \multirow{2}{*}{ Grupo A } & 2 & 0 & 1 & 2 & 0 & 3 \\
& 9 & 0 & 0 & 0 & 2 & 2 \\
\hline \multirow{3}{*}{ Grupo B } & 3 & 0 & 1 & 1 & 2 & 4 \\
& 5 & 0 & 2 & 0 & 1 & 3 \\
& 7 & 0 & 0 & 0 & 1 & 1 \\
\hline \multirow{3}{*}{ Grupo C } & 1 & 2 & 0 & 1 & 1 & 4 \\
& 4 & 2 & 0 & 2 & 1 & 5 \\
& 8 & 2 & 2 & 2 & 1 & 7 \\
& 10 & 0 & 0 & 1 & 1 & 2 \\
\hline
\end{tabular}

1. Índice geral de desempenho $(\mathrm{IGD})=\mathrm{x} 31+\mathrm{x} 32+\mathrm{x} 33+\mathrm{x} 34$.

satisfatório, contradizendo o argumento proposto no que se refere ao tamanho. Para acentuar a situação, a Empresa 1, do Grupo C, de desempenho superior, em conjunto com as empresas do Grupo A, de desempenho inferior, apresentam tamanho médio, sendo portanto difícil concluir sobre a influência dessa variável na definição de estratégias eficientes e no desempenho das empresas.

Em relação à experiência da empresa no mercado externo, embora a empresa de sucesso do Grupo B atue há pouco tempo no mercado, todas as outras empresas de sucesso mostraram-se com ampla experiência nas relações com o mercado internacional, sendo portanto possível inferir que a experiência é um fator condicionante de sucesso das empresas exportadoras de carne de frango.

As vantagens diferenciais da empresa também foram examinadas, por meio de sua eficácia em relação aos concorrentes. De maneira geral, as empresas que alcançam um posicionamento competitivo diante dos concorrentes atuam de maneira mais agressiva no mercado, apresentando melhores condições para adotar estratégias de marketing condizentes com as necessidades do mercado e alcançar um melhor desempenho.

Os resultados analisados revelam que o posicionamento competitivo ante os concorrentes é um fator essencial para a definição de estratégias de marketing adequadas e para o sucesso das exportações. Sua evidência pode ser confirmada, visto que todas as empresas de sucesso adotam uma postura agressiva diante dos concorrentes, contrariamente às empresas de menor sucesso, que apresentam uma atitude mais passiva em relação aos concorrentes. Dentre as estratégias que as empresas de sucesso do Grupo B e do Grupo C adotam para melhorar seu desempenho, destacam-se a diferenciação do produto, a qualidade e o poder de penetração no canal de distribuição.

Apesar de vários resultados estarem consistentes com o que se esperava, é de se notar que algumas variáveis não apresentaram o impacto esperado. Isto pode estar associado ao pequeno tamanho da amostra analisada. Embora as dez firmas que responderam aos questionários sejam responsáveis por parcela expressiva das exportações de carne de frango do Brasil, o pequeno número de empresas não possibilita maior isolamento dos efeitos das variáveis individuais, sendo este problema agravado ainda mais pelo fato de se analisarem trintavariáveis explicativas.

\section{Conclusões}

Os resultados do trabalho permitem concluir que a orientação internacional da empresa, sua experiência e seu posicionamento competitivo diante dos concorrentes destacam-se como os principais determinantes do sucesso das exportações de carne de frango, visto que influenciam positivamente a escolha de estratégias de marketing internacional capazes de sustentar um desempenho satisfatório. Por outro lado, a orientação internacional do administrador, relativa ao nível de instrução, não se mostrou relevante para o sucesso das exportações. Ainda é importante ressaltar a questão referente ao tamanho, visto neste trabalho como parte das vantagens diferenciais da empresa, em que não se chegou a uma situação conclusiva.

Dessa forma, empresas que buscam melhorar o desempenho de suas exportações precisam adotar uma postura ativa, planejando suas operações com o mercado externo e reagindo estrategicamente às questões referentes ao mercado. Não é interessante que as empresas exportem apenas quando ocorrerem pedidos ocasionais no exterior, excessos de produção ou para aproveitar capacidade ociosa. As empresas devem buscar oportunidades no mercado externo, ficando atentas aos desafios e antecipando suas atividades para satisfazer mais os consumidores que os concorrentes e garantir sua participação no mercado.

Para ter sucesso, é essencial que as empresas adotem uma postura agressiva em relação aos concorrentes, principalmente em termos de qualidade, diferenciação de produtos e poder de penetração nos canais de distribuição. Nesse sentido, os resultados sugerem que as empresas exportadoras de sucesso mostram-se dispostas a penetrar em seus mercados, fornecendo produtos diferenciados a seus mercados atuais, e difundindo seus produtos atuais em novos mercados.

Dentre os fatores que não foram considerados importantes para o sucesso da exportação destacam-se o estágio do processo de internacionalização, a orientação internacional do administrador e sua experiência nas relações com o mercado externo.

Contrariamente às expectativas, o estágio do processo de internacionalização não apresentou importância relativa para a definição de estratégias de marketing que ocasionassem sucesso nas exportações. Embora reflita um maior comprometimento e envolvimento nas operações com o mercado externo, as empresas que investiram diretamente no exterior não alcançaram um melhor desempenho, sugerindo que as empresas exportadoras de carne de frango não precisariam, necessariamente, instalar unidades no exterior para obter o sucesso das exportações. Dando suporte a este tipo de argumento, Souza e Ribas (1999) argumentam que a Perdigão, por exemplo, não vê necessidade de se construírem unidades no exterior pelo simples fato de que 
o volume comercializado para os outros países não justifica a dificuldade de superação da burocracia.

No que diz respeito à orientação do administrador, tanto a experiência quanto a formação em comércio exterior, $m a$ rketing ou áreas afins, não se mostraram relevantes para o estabelecimento de estratégias de marketing que levassem ao sucesso das exportações. Esses resultados contrariam as expectativas, pois indicam que o conhecimento do administrador não interfere na tomada de decisões adequadas, em termos de estratégias de marketing internacional.

Dentre as explicações possíveis, pode-se considerar que, muitas vezes, o conhecimento adquirido não se enquadra na realidade da empresa, seja por falta de conhecimentos práticos do administrador, ou mesmo, pela dificuldade das empresas em adaptarem-se às diversas implicações que podem surgir devido a esses conhecimentos. Outra explicação para essa limitação refere-se ao conceito "learning by doing" ou "training on the job". Esse conceito considera que os administradores podem alcançar o sucesso por meio de treinamentos que possibilitem uma conciliação entre o conhecimento e a realização das atividades.

Duas outras importantes considerações a serem salien- tadas refere-se à pequena amostra utilizada na pesquisa e ao tipo específico de pergunta realizada no questionário. A dificuldade de utilizar amostras pequenas, mesmo que representativas, reside na possibilidade de generalizar para todos a realidade de poucos. Já a especificidade da questão utilizada para medir o conhecimento dos administradores, que se concentrou em formação em marketing, comércio exterior ou áreas afins, pode ter limitado as respostas dos administradores, influenciando nos resultados apresentados.

Em relação ao tamanho, suas implicações no desempenho das exportações de carne de frango não foram evidenciadas. Embora empresas maiores possam apresentar certas vantagens, em termos de escala e custos de produção, as empresas exportadoras de carne de frango não precisam, necessariamente, ser grandes para atingirem o sucesso nas exportações. As empresas que trabalham com produtos diferenciados para específicos nichos de mercado, por exemplo, não necessitam de grandes escalas para serem bem sucedidas, pois atendem somente um público seleto. Isso é muito interessante, visto que empresas de pequeno porte podem ter um desempenho satisfatório, no que diz respeito às exportações, independente de sua escala de produção.

\section{Referências Bibliográficas}

AYAL, I. Industry Performance: Assessment and Prediction. Journal of Marketing. 46, p. 54-61, summer, 1982.

BARBOSA, T. R. C. G. Small Firms Competitive Strategy: An Exploratory Study of a Sample of Brazilian Companies. Universidade de Durham. (Tese de doutorado),1991.

BILKEY W. J.; TESAR, G. The Export Behavior of Smallersized Wisconsin Manufacturing Firms. Journal of International Business Studies. v. 13, n.3, p. 93-99, 1977.

HAIR, J. R., et al.. Multivariate Data Analysis. Tulsa: The Petroleum Publishing Company.1979.

JOHNSTON, W. J.; CZINKOTA, M.R. Managerial Motivations as Determinants of Industrial Export Behavior. In M.R. CZINKOTA; G. TESAR (eds.). Export Management. An International Context. New York: Praeger. 1982, p. 3-17.

KIRPALANI, V. H; MACINTOSH, N.B. International Marketing Effectiveness of Technology-oriented Small Fir- ms. Journal of International Business Studies. p. 81-90. 1980.

KOH, A. A. C. Relationships Among Organizational Characteristics, Marketing Strategy and Export Performance. International Marketing Review, v. 8, n. 3, p. 46-60,1991.

KOTLER, P. Administração de Marketing: Análise, Planejamento, Implementação e Controle. São Paulo: Atlas, 1996. $676 \mathrm{p}$.

SILVA, J. C. G. L. Análise da Formulação de Estratégias de Marketing Internacional de Empresas de Papel e Celulose. Piracicaba: Esalq/USP, 1997. 223 p. Tese de Doutorado.

SOUZA, P. H. de; RIBAS, S. Sadia Reforça Marca de Industrializados no Exterior. Jornal Gazeta Mercantil, 15 jul. 1999. C1.

STEVENSON, W. J. Estatística Aplicada à Administração. São Paulo: Harper \& Row da Brasil, 1981. 495 p. 


\title{
Apêndice
}

Quadro A1. Variáveis e formas de medição.

\begin{tabular}{cl}
\hline Variáveis & Formas De Medição \\
\hline X1 a X15 & $\begin{array}{l}\text { (1) Nunca } \\
\text { (2) Raramente } \\
\text { (3) Moderadamente } \\
\text { (4) Freqüentemente } \\
\text { (5) Muito freqüentemente }\end{array}$ \\
\hline (0) De 0 a 7 anos de experiência \\
(1) De 7 a 14 anos de experiência \\
(2) Mais de 14 anos de experiência
\end{tabular}

\section{DETERMINANTS OF THE DEGREE OF ENGAGEMENT IN EXPORT ACTIVITIES AND THEIR IMPLICATIONS IN THE PERFORMANCE OF BRAZIL'S CHICKEN EXPORTS}

\begin{abstract}
This paper analyzes the factors determining the degree of engagement in export activities and verifies their implications in the performance of Brazil's chicken exports. The exporters were first divided into groups by cluster analysis, after which the companies in each group were classified, according to their performance, as more successful or less successful. The results indicated that the company's international experience, its relations with foreign markets, and its competitive approach toward its competitors are the main determinants of its success, for they exert a positive influence on the choice of international marketing strategies that lead to improved performance. Surprisingly, however, the company's degree of internationalization, the manager's international focus and his expertise in relations with foreign markets did not directly affect the choice of international marketing strategies producing a satisfactory performance. No evidence was found that the size of the business influenced its export performance.
\end{abstract}

Keywords: engagement in exports, chicken, export performance. 